\title{
CONSUMER MOTIVES FOR PURCHASING COUNTERFEIT LUXURY PRODUCTS: BEHIND THE STATUS SIGNALING BEHAVIOR USING BRAND PROMINENCE
}

\author{
Pur PURWANTO ${ }^{1}$, Lulus MARGIATI ${ }^{2}$, K. KUSWANDI ${ }^{3}$, Budi PRASETYO ${ }^{4}$ \\ ${ }^{1,2,}{ }^{4}$ WR Supratman University, Surabaya, Indonesia \\ ${ }^{3}$ Mahardhika School of Economic, Surabaya, Indonesia \\ E-mails: ${ }^{1}$ cakpo3r@gmail.com (corresponding author); ${ }^{2}$ lulus.margiati@yahoo.com; \\ ${ }^{3}$ kuswandi56andi@gmail.com; ${ }^{4}$ budi.prasetyo@gmail.com
}

Received 15 January 2019; accepted 22 March 2019

\begin{abstract}
The present study sought to describe the relationship of customer motives with counterfeit products and brand prominence and purchasing behavior in three groups/classes of consumers (patrician, parvenus and poseur) in the context of luxury brand fashion. Data were obtained from a sample consisting of 400 consumers considered eligible. There were three findings; first, for the poseur class, consumer motives for purchasing products had an effect on counterfeit products and conspicuous brand prominence, as well as purchasing behavior. Second, for the parvenus class, consumer motives for purchasing products had no significant effect on counterfeit products, but it had a significant effect on brand prominence and purchasing behavior. Third, for the patrician class, consumer motives for purchasing products had no significant effect on counterfeit products and conspicuous brand prominence, and counterfeit products and brand prominence had no significant effect on purchasing behavior.
\end{abstract}

Keywords: consumer motives, brand prominence, counterfeit products, purchasing behavior.

JEL Classification: M3, M31, M39.

\section{Introduction}

The global losses due to the counterfeiting of luxury/ prestigious brands reached US $\$ 600$ billion annually (Lieber 2014). Distribution of the counterfeit goods (e.g., handbags, glasses, shoes, clothing or accessories) is expected to continually grow in the coming years. Especially in Indonesia, a survey conducted by the Indonesian Anti-Counterfeiting Society (IACS 2015) indicated that counterfeit goods contributed $\$ 612$ billion to national economy during 2015 and caused a loss to the government of approximately $\$ 30$ billion per year from indirect tax revenue. Generally, consumer motives consist of dark/evil motives and good motives for purchasing luxury products (Schiffman and Kanuk 2011, Thaichon and Quach 2016). Specifically, consumers consciously engaged in buying counterfeit products in markets deliberately selling counterfeit products or non-deceptive markets are said to have dark motives (Thaichon and Quach 2016, Bian et al. 2015). Consumers consciously preventing themselves from being engaged in purchasing counterfeit products can be categorized as having good motives.

The motives of consumers of all classes to use luxury products aim to signal a social status (Han et al. 2010, Cannon and Rucker 2018) as a symbol and materialism (Workman and Lee 2011), regardless of whether the product is genuine or not (D'Amato and Thanos 2013). Rather, satisfaction is of ultimate importance since the satisfaction with the status gained from consuming luxury products derives from the audience's reaction. Status is one's position in the social hierarchy as determined by honor and social influence (Ridgeway and Walker 1995).

The levels of social status consist of the patricians, parvenus, poseurs and plebs associated with brand prominence

\footnotetext{
Copyright $\odot 2019$ The Authors. Published by VGTU Press.

This is an Open Access article distributed under the terms of the Creative Commons Attribution License (http://creativecommons.org/licenses/by/4.0/), which permits unrestricted use, distribution, and reproduction in any medium, provided the original author and source are credited..
} 
(Han et al. 2010, Dubois and Duquesne 1992). Brand prominence is a branding concept of a product's quiet (inconspicuous) and loud (conspicuous) logo design (Han et al. 2010). Briefly, the patricians pay a premium for definitely genuine luxury goods within conspicuous brand designs, while the parvenus use genuine luxury products with conspicuous brand designs and the poseurs (the newly affluent) seek to imitate the parvenus by purchasing counterfeit products with conspicuous brands to signal their status to the audience (Wilcox et al. 2008). However, this proposition has been disputed by recent studies (see, D'Amato and Thanos 2013, Perez et al. 2010) indicating a new trend, called "fake chic", in which high-end consumers are fond of purchasing fake products, despite the actual ability to buy genuine luxury products for reasons of a fad, a premium quality (hard to distinguish from the original) or the designation of Thailand originals and/or the location of the sale. Thus, there is an inconsistent motive in each class. Inconsistencies of either Costumer motives, and the behavior of selecting a (quiet vs. loud) brand design of each class to signal their status to others with regard to purchasing prestigious products with prominent brands have not been thoroughly explored by researchers. This is of paramount importance for manufacturers in making brand designs aimed at each class. Therefore, the purpose of the present study was to overcome this gap by developing a framework to describe customer motives with regard to product legality and brand prominence and purchasing behavior in the three groups or classes of consumers simultaneously.

We proposed a hypothesis that consumer (patrician, parvenus and poseur) perceptions of product legality and brand prominence underlie purchase behavior and brand prominence for signaling status. In addition, we tested a model in the three consumer classes or groups. In the next sections, we review the previous studies of customer motives, counterfeit products, and buying behaviors.

\section{Conceptual background and hypotheses development}

\subsection{Consumer motives and counterfeit products}

The literature indicates two prominent motives for consumption, especially as revealed by studies of the consumption of luxury goods today. The first is the motivation of accumulation of wealth, which illustrates an individual image that they belong to the highest, successful and prosperous social circle (Phau and Prendergast 2000). The second motivation is that individuals seek to differentiate themselves or separate themselves from others considered to be of lower levels in order to be more prominent (Veblen 1899). Furthermore, Truong and McColl (2011) also add that self-expression and showing off are regarded as the main motivations and describe success, success and pleasure. The use of counterfeit products aims to remain within the circle of peers and be seen as part of a group, trend, fashion or social class that is equally and even more prominently than those of their community (Tang et al. 2014, Bian et al. 2015). However, the higher classes of consumers (parvenus, patricians) have a negative attitude towards the use of counterfeit products and have high ethical standards (Sharma and Chan 2011, Tang et al. 2014, Chen et al. 2015). On the contrary, among the poseurs, the black motive serves as an important predictor of the purchase of counterfeit products for signaling status (Nwankwo et al. 2014, DeMatos et al. 2007, Wilcox et al. 2008), and has been the behavioral agreement among the users of counterfeit products. A motive or impulse will affect an individual's attitude to behave (Ajzen and Fishbein 1980). An individual's motives depend on the status craved for with regard to the use of a product in the face of the audience. Therefore, the attitude towards the legality of a product will be affected by the status levels. Thus, we propose the following hypothesis:

H1: The higher the consumer class/layer, the less significant the effect of consumer motives on the legality of counterfeit products would be.

\subsection{Consumer motives and brand prominence}

Brand prominence describes a conspicuous or inconspicuous mark on a product, such as the "G" of Gucci or a thick red and green striped signature on a bag to make sure that the person seeing it recognizes it as a Gucci brand. McFerran et al. (2014) states that the design of a brand (logo) on a product serves as a symbol or a signal. The choice of luxury product brand can signal a social cue to consumers and the status of the user (Piff 2014, Wang and Griskevicius 2013). The brand shape, whether loud or quiet, constitutes a consumer motive to buy counterfeit luxury branded products (Bagheri 2014). Conspicuous logos can be easily seen and recognizable by others, especially for people who are less familiar with famous luxury brands (Han et al. 2010). Thus, consumers motives to use genuine or counterfeit luxury goods may have an effect on the choice of a conspicuous or inconspicuous brand in order to signal a status to an equal or lower class. Thus, we propose the following hypothesis:

H2: Customer motives to buy luxury branded products have a significant effect on brand prominence (loud or quiet) in all classes (patrician, parvenus and poseur).

\subsection{Counterfeit products and brand prominence}

Consumers buy counterfeit luxury branded products due to a desire to have luxury goods but cannot afford or do not want to pay at a premium. Counterfeit goods are subjected to fashion hunters to signal their status to others (Jiang and 
Cova 2012) since excellent counterfeit goods are in lieu of the genuine ones, giving social and personal meanings. Brand prominence predominantly serves as an important consideration for the poseurs to buy counterfeit luxury branded products. They tend to much cheaper products with more conspicuous logos, especially for consumers (Bagheri 2014). They crave a status through purchasing counterfeit goods with conspicuous brands and cheaper prices to signal to others. Specifically, the parvenus have the need for displaying brands prominently since they are not accustomed to recognize and assess genuine luxury goods and expect the audience to recognize them quickly (Erdem and Swait 1998). The patricians seek to stay away from the motive of buying counterfeit products with conspicuous brands (Han et al. 2010). Thus, brand prominence (loud vs. quiet) will be considered when buying counterfeit luxury branded products. Thus, we propose the following hypothesis:

H3: Favoring brand prominence with conspicuous brand designs is the customer motive to buy counterfeit luxury branded products.

\subsection{Counterfeit products and brand prominence and purchasing behavior}

According to the theory of planned behavior, attitudes are the most influential factors predicting deliberate behaviors (Ajzen and Fishbein 1980). The attitude to using counterfeit luxury branded products is the most influential factor of intentional behavior (Riquelme and Sayed-Abbas 2012). Thus, the characteristics of counterfeit products have a positive effect on consumers' buying behavior. The previous study has shown that brand prominence also provides a certain brand image of (conspicuous or inconspicuous) counterfeit products affecting buying behavior (Bian and Moutinho 2011a). Thus, we propose the following hypothesis:

H4: Consumers' positive attitudes towards counterfeit luxury branded products has a significant effect on purchase behavior.

H5: Consumers more strongly favoring brand prominence have counterfeit-product purchase behaviors.

\section{Methodology}

\subsection{Procedures and samples}

The survey was conducted on Indonesian consumers encountered in some places, such as famous boutiques selling genuine branded products, famous malls in metropolitan cities, and some retailers accustomed to selling counterfeit goods in Batam, Jakarta, Bandung, Bali and Surabaya. Sampling procedures were carried out carefully, given that grouping of classes or layers into patricians, parvenus or poseurs was deliberately not informed to the respondents; rather, it was only based on their type of signaling and the expertise and the need for status. Despite our belief that wealth is an indication of each class they occupy, we did not explicitly examine it. Questionnaires were distributed by involving 60 students, in which each student distributed 10 questionnaires to anyone who was shopping in the predetermined places. The respondents were asked to name one product they had bought for a certain period of time and encircle their perception of the product.

\subsection{Characteristics of samples}

A total of 600 questionnaires were distributed to respondents, of which 400 (66.6\%) were considered eligible. The majority $67.75 \%$ of respondents were female and the remaining $32.25 \%$ were men and their age ranged from 25 to 60 years (mean $=35.1$ and median 32 ). The sample size of each group or class of consumers is as follows: the patricians were 98 (24.5\%) respondents, the parvenus were 179 (44.75\%) respondents and the poseurs were 123 (30.75) respondents.

\subsection{Measures}

We developed questionnaire items from previous studies to measure consumer motives toward counterfeit products and brand prominence, such as "I use counterfeit luxury brands to look like a successful person," "The price difference between counterfeit and genuine luxury goods is very high," "I know that this is not the best thing to do but I want to experience wearing counterfeit luxury goods without spending a lot of money," "It's great when I can carefully distinguish counterfeit from genuine luxury products (Bian et al. 2015, Stöttinger and Penz 2015, Tang et al. 2014, Chiu and Leng 2016) to measure the choice of brand prominence and counterfeit products. We developed the questionnaire based on three studies (Wilcox et al. 2008, Han et al. 2010), such as "Buying a luxury product with a conspicuous brand design makes me proud," "Conspicuous brand designs are widely available on the black market," and "Inconspicuous brand design aims to disguise counterfeit luxury products" to measure buying behaviors with regard to consumer attitudes toward counterfeit luxury products. Consumers have a positive attitude toward purchasing counterfeit products when the prices are much cheaper, the products have an almost equal quality and they are willing to buy counterfeit products or otherwise (Requelme and Sayed-Abbas 2012, Hoppe et al. 2013). Furthermore, Cannon and Rucker (2018) also adds an item, "Being willing to continue to use counterfeit goods, I advise others to buy counterfeit products." For all items, we used a Likert-type scale with seven points (1, strongly disagree; 7 , strongly agree).

Respondents were also asked to indicate which luxury brands they had ever bought and whether they favored 
either inconspicuous (patrician) or conspicuous (parve$n u s$ ) designs. When a respondent declared choosing an inconspicuous brand design, he or she was asked to indicate whether his or class would recognize what type of item he or she was using. Respondents who declared choosing a conspicuous brand design in order to accentuate that the goods they were using were luxury goods were also given a question related to their experience with luxury but counterfeit products. Lastly, in order to determine the poseurs, samples were taken in places selling counterfeit/pirated products freely.

\section{Analysis and results}

\subsection{Confirmatory factor analysis (CFA)}

The mean, standard deviation, construct reliability, average variance extracted (AVE) and bivariate correlation among each latent factors can be found in Table 1 . The measurement model indicates a fit with the results $\left(\chi^{2}=2505.16\right.$; $p<.01 ; d f=1.402 ; \mathrm{TLI}=0.88 ; \mathrm{RMSEA}=0.06$; $\mathrm{SRMR}=0.07$ ). The items entered into the measurement model have an estimated convergent validity ranging from 0.76 to 0.90 , meaning that they are quite reliable. The latent constructs entered into the CFA show strong evidence since all items have a high level of significance. This indicates that the items strongly account for the error variances (Fornell and Larcker 1981). Additionally, the AVE of each latent variable exceeds 0.50 , indicating that the variance caused by measurement errors is smaller than that caused by the constructs. Simultaneously, convergent validity provides strong evidence that supports the scale of consumer motives, counterfeit products, brand prominence and purchasing intention. Finally, the AVE for all constructs exceeds the joint variance among the constructs and all other variables; thus, the discriminant validity proves strong (Fornell and Larcker 1981).

\subsection{Hypothesis testing}

To analyze whether $\mathrm{H} 1$ to $\mathrm{H} 5$ are proven in the patricians, parvenus and poseurs, data were categorized into three groups and parameter estimates $(\gamma$ and $\beta$ ) freely for each group using LISREL 9.1. Furthermore, all parameter estimates for a particular class group (e.g., patricians) that were similar to those of other class group (e.g., parvenus) were constrained. To evaluate the difference in fit between an unconstrained and constrained model the $\chi^{2}$ difference test was used. The difference between two $\chi^{2}$ values ranged from 22 to $136(d f=7 ; p=0.05)$ for the three class groups, indicating that the two constrained and unrestricted groups differed significantly on the estimated parameters.

The unconstrained model for poseurs $(\mathrm{n}=123)$ had a moderate general fit $\left(\chi^{2}=451.0\right.$; $\mathrm{df}=142 ; p<.05$; CFI $=$ .94 ; GFI $=.89$; TLI $=0.86$; RMSEA $=0.07$; SRMR $=0.05$ ). Despite the robust foundation of the model, the potential model specifications should be considered to determine the extent to which the conceptualization that captured that data could improve validity (Anderson and Gerbing 1988). For the poseur model, we identified one additional path from counterfeit products to brand prominence. Since the poseurs have fewer experiences with genuine luxury brands and even tend to look for counterfeit goods (Han et al. 2010) their expectations are lower than those of the parvenus with regard to status signaling. When the poseurs find counterfeit luxury goods with conspicuous brands they are more inclined to make a purchase than the parvenus (the class right above). Therefore, this class feels proud and believes that they are the savvy and experienced buyers who choose the best and affordable counterfeit luxury goods, relative to the two classes above them. Such feelings serve to stimulate customer (dark) motives and make them confident in buying counterfeit luxury goods (see, Bian and Moutinho 2011a, Stöttinger and Penz 2015). Thus, the path between customer motives and purchasing intention via brand prominence and counterfeit products can be proved for the poseurs class, as shown in Figure 1. Results showed that all the parameter estimates were significant, supporting $H 1$ to $H 5$. The value of $\chi^{2}$ was $447.7(d f=141)$, lower than that of the initial model $\left(\chi^{2}=451.0, d f=142\right)$, and CFI was 0.94, GFI 0.89, TLI 0.86, RMSEA 0.07 and SRMR 0.05. The difference between the two values of $\chi^{2}$ was 3.3 , greater than the significance level of $2.51(\chi 0.05,12)$.

In addition, the coefficient of $\gamma_{22}$ was 0.04 , which was also significant at $p<0.05$. These results indicate the model fit is acceptable, as shown in Figure 1 in which it is significantly higher than that of the initial model, which does

Table 1. Descriptive statistics, intercorrelations, and Confirmatory Factor Analysis (CFA) results

\begin{tabular}{|c|c|c|c|c|c|c|c|c|c|c|c|}
\hline & Variable & $\mathrm{M}$ & SD & $\alpha$ & CR & AVE & 1 & 2 & \multicolumn{2}{|c|}{3} & 4 \\
\hline 1. & Consumer motive & 5.30 & 0.85 & .78 & .75 & .71 & .76 & & & & \\
\hline 2. & Product Counterfeit & 5.15 & 1.18 & .93 & .91 & .74 & $-.22 * *$ & .87 & & & \\
\hline 3. & Brand prominence & 5.11 & 1.07 & .96 & .95 & .83 & $-.23^{\star \star}$ & $.79^{\star *}$ & .88 & & \\
\hline 4. & Purchasing behavior & 5.74 & 0.93 & .92 & .90 & .75 & $-.22^{\star *}$ & $.67^{\star *}$ & $.75^{\star \star}$ & $.72^{\star *}$ & .90 \\
\hline
\end{tabular}

Note: $\mathrm{N}=400 . \dagger p<.10 .^{*} p<.05 .^{* *} p<.01$. 


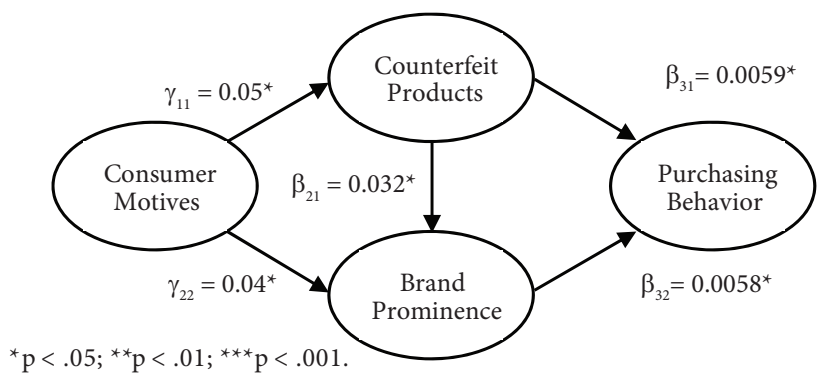

Figure 1. The poseurs

not contain the path from counterfeit products to brand prominence.

The unconstrained model for patricians $(n=98)$ (Figure 2) had $\chi^{2}$ of $236.5(d f=143, p<0.05)$, CFI of 0.91 , GFI of 0.85 , TLI of 0.88 , RMSEA of 0.06 , and SRMR of 0.07 ; thus, in general, the model was acceptable. However, 5 paths were not significant in Figure 2. The paths from customer motives to counterfeit products and brand prominence $\left(\gamma_{23}=0.73, p>.05\right)$ were not significant since the patricians are disdainful and have a negative emotion towards counterfeit luxury products brands. Finally, the relationship between counterfeit products and brand prominence and purchasing behavior was also insignificant $(\beta=0.72$, $0.35, p>0.05$ ), indicating that the perception of counterfeit products and brand prominence does not lead this class to make purchases and even respond to them negatively. However, there are also consumer (dark motives) behind the purchase of counterfeit luxury goods with inconspicuous (quiet) brands with the aim to disguise that this class never buy counterfeit goods since some respondents claimed interested in trying the sensation of looking for counterfeit goods in black markets (e.g. Sharma and Chan 2011, Chen et al. 2015). This can also be explained by the interviews with some respondents who were considered an elite class (entrepreneur family members, celebrities). Thus, one direct path from customer motives to purchasing behavior could be added and proved significant $(\gamma=0.02 ; p>0.05)$; this is what is call the dark motive of the patricians. This is also supported by the currently growing perception that whatever the entrepreneurs, high-level officials, celebrities,

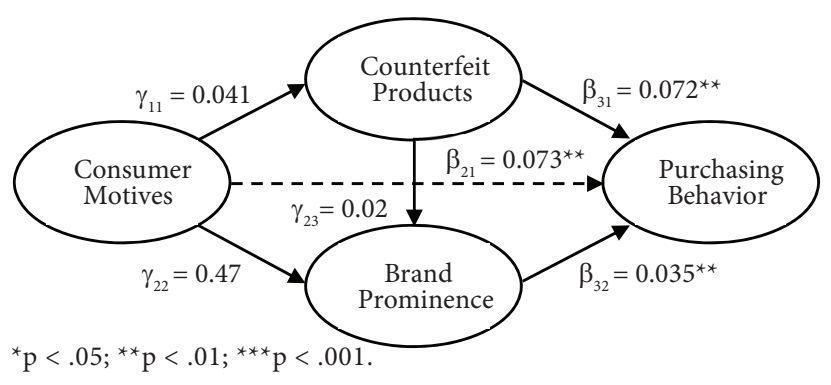

Figure 2. The patricians

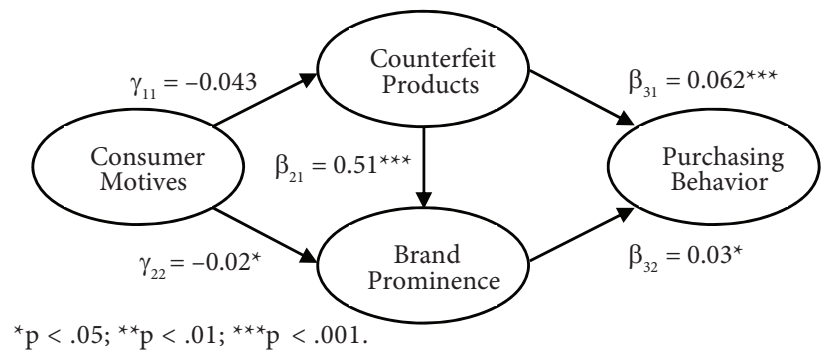

Figure 3. The parvenus

and well-known lawyers are wearing, the public believe that their goods are luxurious and expensive ones.

For the unconstrained model of the parvenus $(n=179)$ (Figure 3) the $\chi^{2}$ was $282.5(d f=143 ; p<0.05)$, CFI 0.92, GFI 0.83, TLI 0.86, RMSEA 0.08 and SRMR 0.07; thus, the model fit is generally acceptable. As shown by Figure 3 , the significant paths are from customer motives to loud brand prominence $(\gamma=0.02 ; p<0.05)$ and from brand prominence to consumer purchasing behavior $(\beta=0.03 ; p<0.01)$. This class had a negative attitude toward counterfeit products since they want to build a positive image that they were the newly rich people who craved the status of their group and that of the class above them.

Therefore, the path of customer motives to counterfeit products was not significant. Despite this class' awareness of counterfeit product characteristics, but they were quite careful with regard to the legality of luxury goods since they did not want to undermine the social status they were building.

\subsection{Discussion}

Results of our analysis support our predictions that the need for status for the poseurs can only be fulfilled by buying counterfeit products with conspicuous brands since this class is highly price-sensitive and does not afford to buy genuine products. The parvenus has the motive of using genuine conspicuous branded luxury products as a signal to make it clear that they are not part of the lower (poseur) class. The parvenus consider the patricians an aspirational group whereas the poseurs a dissociative group (White and Dahl 2006). They prefer popular luxury products with conspicuous brand in order to be more easily recognizable. For example, Louis Vuitton's distinctive, conspicuous "LV" monogram or Chanel brand which are favorites among red-carpet actresses are craved for by this class.

Finally, the patricians who have the expertise and experience with luxury products and possess significant wealth buy products not to be deliberately exhibited to the class below since they consider themselves exclusive/superior (Dubois and Duquesne 1992). they consider purchasing luxury goods a pleasure or an art of living. For example, they buy a Hublot Big Bang watch for US $\$ 5$ million but this item 
looks ordinary to those below. This class uses luxury products to serve as a signal of elegance and good taste (Cannon and Rucker 2018, Han et al. 2010). They signal their status in abstract ways, which are difficult to recognize by those below. Being very exclusive, some people (patricians) buy (dark motive) fake luxury products with rare, inconspicuous brands. Despite the detrimental nature of this behavior to their group, capable of degrading their dignity in general, but they regard doing it as solely for pleasure since they assume that the classes below them do not recognize it. This is what we call a "fake chic", in which consumers actually afford to buy genuine luxury goods but, since they are more familiar with counterfeit (quality, manufacturers) products, they attempt to buy it. In addition, there is a presumption that what is being used by the patricians is always perceived as a genuine luxury product (Han et al. 2010, D'Amato and Thanos 2013).

\section{Conclusions}

In conclusion, the patricians, parvenus and poseurs vary in terms of expertise and the need for status, which motivate (dark or good) how they intend to use (genuine or counterfeit) luxury goods for status signaling (Nelissen and Meijers 2012). The expertise of signaling status implies consumers' having to be well aware of product prices and knowledge and other cues of quality (Alba and Hutchinson 1987). The most elite (patrician) class does not rely on conspicuous brands that serves as a signal, while the newcomers (parvenus) requires conspicuous brands to convey their messages. The poseurs attempt to emulate the parvenus by buying counterfeit, even more conspicuous products.

The patrician class can describe very subtle gestures while the parvenus, which is the reference for the poseur, is attracted to the striking brand as a sign that the brand it wears is expensive. It aims to explain to the world that the parvenus class has succeeded. They tell the poor (poseur) that they are richer and to the class on it (patrician) that they are part of the group. There is something paradoxical in the findings of this research especially in the patrician class, that this class is a collection of highly consistent elites towards the use of genuine luxury products, but there are few people who actually tarnish the excitement of anticounterfeit consumption behavior, few people this has a unique reason like fun, try it, assume that other people do not know it. However, these findings can't be justified that the class of patricians all do so, this is merely a person who is not responsible for the existence of the patrician class.

\section{Managerial implications}

Brand design is of importance for the manufacturers of luxury goods, with regard to managing product lines appropriately and attracting the middle class to higher levels (Gumbel 2007). The trickle-down theory may serve as a reference. For example, a haute couture event can be used by a fashion house to introduce its designs to consumers desiring to have a custom-made dress with a relatively inexpensive price and a more moderate/elegant design with the aim of being the attraction for the underclass (Gumbel 2007). The findings of the present study also demonstrated that conspicuous and cheaper products were aimed at the poseurs and more expensive and less conspicuous products were aimed at the elite patricians, while conspicuous products were aimed at the parvenus. This dichotomy may certainly trigger manufacturers operating in the black market to produce more profitable and clearly segmented counterfeit products. We also demonstrated that manufacturers of luxury goods can target two types of customers simultaneously with varied brand prominence and price variations across products of a single brand in different classes. Therefore, the application of price dynamics can also be.

\section{Limitations and further research}

The present study has two major limitations. First, This study examined individuals' behaviors of using a variety of luxury brands for status signaling, but it did not address the extent to which the audience respond to such signals as desired. This remains questionable (Han et al. 2010, Eastman et al. 1999). Thus, it opens an opportunity for further research on how to interpret responses to signals transmitted by the sender and also what are the patterns of interaction between the sender and the receiver.

Third, this study clearly distinguished the tastes of each class with regard to brand designs. A question arises whether companies marketing conspicuously branded goods would erode the status of their products? Likewise, does the range of products designed with inconspicuous brands help improve the status of products? It is an interesting direction for further research to examine the effects of brand designs on the users' status and the products' status tailored to individuals' lifestyles and personalities. It is possible that the categorization into patricians, parvenus and poseurs is no longer relevant to one's character, in particular Indonesian people.

\section{References}

Ajzen I, Fishbein M (1980) Understanding attitudes and predicting social behavior: Attitudes, intentions, and perceived behavioral control. Englewood Cliffs, NJ: Prentice Hall, 148-172.

Alba JWJ, Hutchinson W (1987) Dimensions of consumer expertise. Journal of Consumer Research (13): 411-454. https://doi. org/10.1086/209080

Anderson J, Gerbing D (1988) Structural equation modeling in practice: a review and recommended two step 
approach. Psychology Bulletin 103 (May): 411-423. https:// doi.org/10.1037/0033-2909.103.3.411

Bagheri M (2014) Luxury consumer behavior in Malaysia: Loud brands vs. Quiet brands. Procedia - Social and Behavioral Sciences (130): 316-324. https://doi.org/10.1016/j. sbspro.2014.04.037

Bian X, Moutinho L (2011a) The role of brand image, product involvement, and knowledge in explaining consumer purchase behaviour of counterfeits. European Journal of Marketing, 45 (1/2): 191-216. https://doi.org/10.1108/03090561111095658

Bian X, Haque S, Smith A (2015) Social power, product conspicuousness, and the demand forluxury brand counterfeitproducts. Journal Social Psychology (54): 37-54. https://doi. org/10.1111/bjso.12073

Cannon C, Rucker DD (2018) The dark side of luxury: Social costs of luxury consumption. Personality and Social Psychology Bulletin, 1-13. https://doi.org/10.1177/0146167218796790

Chen J, Teng L, Liu S, Zhu H (2015) Anticipating regret and consumers' preferences for counterfeit luxury products. Journal of Business Research (68): 507-515. https://doi.org/10.1016/j. jbusres.2014.09.012

Chiu W, Leng HK (2016) Consumers' intention to purchase counterfeit sporting goods in Singapore and Taiwan. Asia Pacific Journal Marketing Logistic 28 (1): 23-36. https://doi. org/10.1108/APJML-02-2015-0031

D’Amato I, Thanos P (2013) Legitimate vs illegitimate: The luxury supply chain and its doppelganger. International Journal of Retail \& Distribution Management 41 (11/12): 986-1007. https://doi.org/10.1108/IJRDM-01-2013-0015

DeMatos CA, Cristian TI, Calos Alberto VR (2007) Consumer attitudes toward counterfeits: A review and extension. Journal of Consumer Marketing 24 (1): 36-47. https://doi. org/10.1108/07363760710720975

Dubois B, Duquesne P (1992) The market for luxury goods: Income versus culture. European Journal of Marketing 27 (1): 35-44. https://doi.org/10.1108/03090569310024530

Eastman JK, Ronald EG, Flynn RL (1999) Status consumption in consumer behavior: Scale development and validation. Journal of Marketing Theory and Practice 7 (Summer): 41-52. https:// doi.org/10.1080/10696679.1999.11501839

Erdem T, Swait J (1998) Brand equity as a signaling phenomenon. Journal of Consumer Psychology 7 (2): 131-57. https://doi. org/10.1207/s15327663jcp0702_02

Fornell C, Larcker DF (1981) Evaluating structural equation models with unobservable variables and measurement error. Journal of Marketing Research 18 (1): 39-50. https://doi. org/10.2307/3151312

Gumbel P (2007) Luxury goes mass market, fortune magazine, the business of luxury http://money.cnn.com/2017/30/magazines/fortune/massvsclass.fortune/index.htm

Han YJ, Nunes JC, Drèze X (2010) Signaling status with luxury goods: The role of brand prominence. Journal of Marketing 15 (74): 15-30. https://doi.org/10.1509/jmkg.74.4.15

Hoppe A, Vieira LM, Barcellos MD (2013) Consumer behaviour towards organic food in porto alegre: an application of the theory of planned behaviour. Revista de Economia e Sociologia Rural 51 (1): 69-90. https://doi.org/10.1590/S010320032013000100004
IACS (2015) Counterfeiting is a growing industry in Indonesia https://www.amcham.or.id/en/news/detail/countering-counterfeiting-in-indonesia

Jiang L, Cova V (2012) Love for luxury, preference for counterfeits a qualitative study in counterfeit luxury consumption in china. International Journal of Marketing Studies 4 (6): 1-9. https://doi.org/10.5539/ijms.v4n6p1

Lieber C (2014) Why the $\$ 600$ billion counterfeit industry is still horrible for fashion https://www.racked.com/2014/12/ 1/7566859/counterfeitfashiongoodsproductsmuseumexhibit

McFerran AB, Karl Aquino B, Tracy JL (2014) Evidence for two facets of pride in consumption: Findings from luxury brands. Journal of Consumer Psychology 24 (4): 455-471. https://doi. org/10.1016/j.jcps.2014.03.004

Nelissen MA, Meijers HC (2012) Social benefits of luxury brands as costly signals of wealth and status. Evolution and Human Behavior 32 (5): 343-355. https://doi.org/10.1016/j.evolhumbehav.2010.12.002

Nwankwo S, Hamelin N, Khaled M (2014) Consumer values, motivation and purchase intention for luxury goods. Journal Retailer Consumer Service 21(5): 735-744. https://doi. org/10.1016/j.jretconser.2014.05.003

Perez ME, Castan'o R, Quintanilla C (2010) Constructing identity through theconsumption of counterfeit luxury goods. Qualitative Market Research: An International Journal 13 (3): 219-235. https://doi.org/10.1108/13522751011053608

Phau I, Prendergast G (2000) Consuming luxury brands: The relevance of the rarity principle. The Journal of Brand Management 8 (2): 122-138. https://doi.org/10.1057/palgrave.bm.2540013

Piff PK (2014) Wealth and the anflated aelf class, entitlement, and narcissism. Personality and Social Psychology Bulletin 40 (1): 34-43. https://doi.org/10.1177/0146167213501699

Ridgeway CL, Walker HA (1995) Status structures in sociological perspectives on social psychology. Upper Saddle River NJ: Pearson Education, 281-310.

Riquelme HE, Sayed-Abbas EM (2012) Intention to purchase fakeproducts in an Islamic country. Education, Business and Society: Contemporary Middle Eastern Issues 5 (1): 6-22. https://doi.org/10.1108/17537981211225835

Sharma P, Chan RY (2011) Counterfeit proneness: conceptualization and scale development. Journal Marketing Management 27 (5-6): 602-626. https://doi.org/10.1080/026725 7X.2010.489829

Schiffman LG, Kanuk LL (2011) Consumer Behavior $\left(10^{\text {th }}\right.$ Ed). New Jersey: Prentice Hall.

Stöttinger B, Penz E (2015) Concurrent ownership of brands and counterfeits: conceptualization and temporal transformation from a consumer perspective. Psychology Marketing (32): 373-391. https://doi.org/10.1002/mar.20786

Tang F, Tian V I, Zaichkowshy J (2014) Understanding counterfeit consumption. Asia Pacific Journal of Marketing and Logistics 26 (1): 4-20. https://doi.org/10.1108/APJML-11-2012-0121

Thaichon P, Quach S (2016) Dark motives counterfeit purchase framework: Internal and external motives behind counterfeit purchase via digital platforms. Journal of Retailing and Consumer Services (33): 82-91. https://doi.org/10.1016/j. jretconser.2016.08.003 
Truong Y, McColl R (2011) Intrinsic motivations, self-esteem, and luxury goods consumption. Journal of Retailing and Consumer Services (18): 555-561. https://doi.org/10.1016/j. jretconser.2011.08.004

Veblen T (1899) The theory of the leisure class. New York: Penguin.

Wang Y, Griskevicius V (2013) Conspicuous consumption, relationships and rivals: Women's luxury products as signals to other women. Journal of Consumer Research 40 (5): 834-854. https://doi.org/10.1086/673256

Wilcox K, Hyeong MK, Sen S (2008) Why do consumers buy counterfeit luxury brands. Forthcoming in the Journal of Marketing Research 46 (4): 247-259.
White K, Dahl DW (2006) To Be or Not Be? The influence of dissociative reference groups on consumer preferences. Journal of Consumer Psychology 16 (4): 404-413. https://doi.org/10.1207/ s15327663jcp1604_11

Workman JE, Lee SH (2011) Materialism, fashion consumers and gender: A cross-cultural study. International Journal of Consumer Studies 35 (1): 50-57. https://doi.org/10.1111/j.14706431.2010.00935.x 